\title{
Is physical capacity correlated with health-related quality of life in patients with adolescent idiopathic scoliosis?
}

\author{
Hui Cong ${ }^{1}$, Lixia Chen ${ }^{2}$, Jianxiong Shen ${ }^{3}$, Wangshu Yuan², Youxi Lin ${ }^{3}$, Zhaoyu Liu ${ }^{4}$, Shufen Liu², \\ Lu Zhang ${ }^{2}$
}

${ }^{1}$ Department of Healthcare, Peking Union Medical College Hospital, Peking Union Medical College, Chinese Academy of Medical Sciences, Beijing, China; ${ }^{2}$ Department of Physical Medicine and Rehabilitation, Peking Union Medical College Hospital, Peking Union Medical College, Chinese Academy of Medical Sciences, Beijing, China; ${ }^{3}$ Department of Orthopaedics, Peking Union Medical College Hospital, Peking Union Medical College, Chinese Academy of Medical Sciences, Beijing, China; ${ }^{4}$ Department of Outpatient Office, Peking Union Medical College Hospital, Peking Union Medical College, Chinese Academy of Medical Sciences, Beijing, China

Contributions: (I) Conception and design: L Chen, H Cong; (II) Administrative support: L Chen, J Shen; (III) Provision of study materials or patients: J Shen, Y Lin; (IV) Collection and assembly of data: H Cong, S Liu, L Zhang; (V) Data analysis and interpretation: W Yuan, Z Liu; (VI) Manuscript writing: All authors; (VII) Final approval of manuscript: All authors.

Correspondence to: Dr. Lixia Chen. Department of Physical Medicine and Rehabilitation, Peking Union Medical College Hospital, No.1 Shuaifuyuan Wangfujing, Dongcheng District, Beijing 100730, China. Email: chenlx_pumch@163.com.

Background: There have been no report about the association between physical capacity and healthrelated quality of life in patients with adolescent idiopathic structural scoliosis (AIS). This study aims to investigate the correlation between dynamic cardiopulmonary capacity and quality of life in AIS patients.

Methods: This retrospective study involved 63 patients. Correlations between cardiopulmonary exercise test parameters and Scoliosis Research Society (SRS)-22 scores were evaluated using Spearman's correlation test.

Results: Fifty-four female patients [mean age: 14.1 (range, 10-19) years] and 9 male patients [15.9 (range, 14-19) years] with AIS (Cobb angle: $28^{\circ}-86^{\circ}$ ) were included. Significant correlations were found between the peak oxygen uptake normalized by body weight and the SRS-22 scores in female patients, as reflected by the function $(\mathrm{r}=0.511, \mathrm{P}<0.001)$, pain $(\mathrm{r}=0.418, \mathrm{P}=0.002)$, mental health $(\mathrm{r}=0.536, \mathrm{P}<0.001)$ and subtotal $(\mathrm{r}=0.618, \mathrm{P}<0.001)$ scores. Significant correlations were also found between oxygen uptake at anaerobic threshold normalized by body weight and the SRS-22 scores in female patients, as reflected by the function $(\mathrm{r}=0.404, \mathrm{P}=0.002)$, pain $(\mathrm{r}=0.455, \mathrm{P}=0.001)$, and subtotal $(\mathrm{r}=0.501, \mathrm{P}<0.001)$ scores, along with respiratory exchange ratio reflected by subtotal $(\mathrm{r}=0.464, \mathrm{P}<0.001)$ score.

Conclusions: The physical capacity and capacity for the exercise intensity and endurance correlated with quality of life among patients with AIS. Exercise may better the quality of life of patients with AIS.

Keywords: Adolescent idiopathic scoliosis (AIS); physical capacity; cardiopulmonary exercise test; Scoliosis Research Society-22 (SRS-22); quality of life

Submitted Dec 30, 2020. Accepted for publication Apr 28, 2021.

doi: 10.21037/apm-20-2624

View this article at: http://dx.doi.org/10.21037/apm-20-2624

\section{Introduction}

Adolescent idiopathic scoliosis is the most common type of spinal deformity (1), accounting for $80-85 \%$ of the scoliosis cases (2). According to the current literature, the overall prevalence of adolescent idiopathic scoliosis is
$0.47-5.2 \%$ (3). Because adolescent development is affected by physical, psychological, and social changes, increased attention is provided to patients' health-related quality of life with idiopathic scoliosis (4-8).

Spinal and chest deformities affect pulmonary and 
cardiovascular functions in patients with scoliosis (9), likely resulting in decreased physical capacity (10-12). This finding is supported by the results of earlier studies that demonstrated lower maximum oxygen intake and lesser tolerance to maximal exercise among patients with adolescent idiopathic scoliosis (10,11,13-15). Moreover, studies have suggested that the lower maximum oxygen intake appears to influence the reduced tolerance to exercise among these patients $(10,11,13-15)$. Reduction in physical capacity may negatively influence patient activities (Sperandio, 2014), possibly affecting their quality of life, especially among adolescents (16). To date, there have been no studies conducted on the association between physical capacity and health-related quality of life. In this study, we examined whether or not patients' physical capacity with adolescent idiopathic scoliosis is associated with healthrelated quality of life. In addition, because earlier studies have suggested gender-based differences in adolescent idiopathic scoliosis $(17,18)$, we examined possible genderbased differences.

We present the following article in accordance with the STROBE reporting checklist (available at http://dx.doi. org/10.21037/apm-20-2624).

\section{Methods}

\section{Study design}

This retrospective study included patients with adolescent idiopathic scoliosis who visited our orthopedic center and underwent a cardiopulmonary exercise test from June 2016 to December 2017. These patients were recruited before receiving the scheduled surgery at our center. Many patients with severe scoliosis delayed the prescribed surgeries because of financial restrictions or the unavailability of medical resources. Patients aged between 10 and 19 years were included in the study, whereas those with any of the following factors were excluded: (I) combined sagittal hyper-kyphosis or hyper-lordosis, (II) a history of spinal surgery, and (III) incomplete clinical and Scoliosis Research Society-22 (SRS-22) questionnaire data. A total of 9 male and 54 female patients were included in the study. The study was conducted in accordance with the Declaration of Helsinki (as revised in 2013). The study was approved by the Institutional Review Board (IRB) of Peking Union Medical College Hospital (PUMCH) (NO. S-K209). Written informed consent was obtained from all the individual participants or their guardians included in this study.
Data on age, height, weight, and Cobb's angle were obtained from the patients' medical records. Hyperkyphosis is defined as the Cobb angle of kyphosis, calculated from a lateral radiograph using T4 and T12 as landmarks, is $40^{\circ}$ or more. Hyper lordosis is defined as the Cobb angle of kyphosis, calculated from a lateral radiograph using L1 and $\mathrm{S} 1$ as landmarks, is more than $60^{\circ}$. In addition, we primarily focused on cardiopulmonary performance during exercise. During the visit, each patient performed the cardiopulmonary exercise test using a motor-driven cycle ergometer (Master Screen; CareFusion), conducted by the same physician specialist. The test protocol was established following the ATS/ACCP Statement on Cardiopulmonary Exercise Testing (19). In our study, the speed of the bicycle was maintained at 55 to 60 revolutions per minute, and the test started with a 3-min warm-up at $0-\mathrm{W}$ labor, followed by increases in the resistance increments of 10, 15, 20, 25 , and $30 \mathrm{~W} / \mathrm{min}$. Patients generally reached maximal exercise capacity within 8 to $10-\mathrm{min}$. When the patient attained the scheduled heart rate or experiencing intolerable discomfort, the labor was reduced. The main parameters that characterized physical capacity were recorded and analyzed (19-21), specifically maximal load, oxygen uptake at anaerobic threshold, peak oxygen uptake, the volume of carbon dioxide produced, respiratory exchange ratio, oxygen pulse (oxygen uptake/heart rate, reflecting the amount of oxygen extracted per heat beat), ventilation volume per minute, and maximal voluntary ventilation.

Patient quality of life was assessed using the SRS-22 questionnaire. The questionnaire assesses five domains: function, pain, self-image, mental health, and subtotal $(22,23)$. All patients completed the questionnaire within 5 min after the exercise test.

The flowchart of the exercise test is shown in Figure 1.

\section{Statistical analysis}

Because earlier studies reported gender-based differences in patients with adolescent idiopathic scoliosis $(17,18)$, analyses for male and female patients were performed separately. Cardiopulmonary exercise test parameters and SRS-22 domain scores are presented as means and standard deviations for the total population and male and female participants. The gender-based differences were tested using a parametric test (Student's $t$-test) for normally distributed continuous variables and a nonparametric test (Wilcoxon signed-rank test) for skewed continuous variables.

Due to the small number of males, Spearman's 


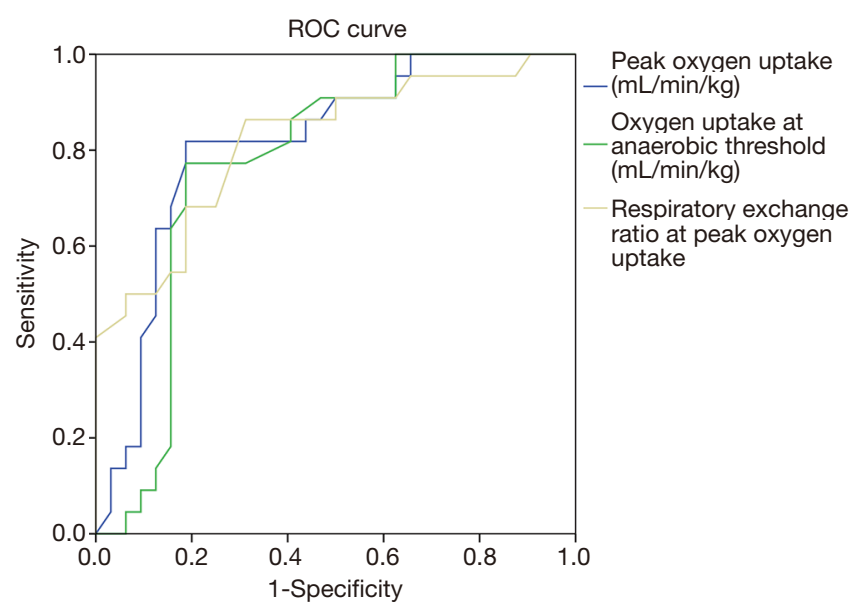

Figure 1 Flowchart of the exercise test.

correlation coefficient was calculated using an individual non-transformed variable for the correlations between cardiopulmonary exercise testing parameters and SRS22 domain scores only in women. Variables (respiratory exchange ratio and oxygen uptake) having significant correlations with the SRS-22 domain scores $(\mathrm{P}<0.0025)$ were further included in the multivariable model to compute the area under the receiver operating characteristic (ROC) curve. This process was chosen to test the discriminatory ability of the model with the outcome of the binary score by using the median as the cutoff value. All statistical analyses were performed using the SPSS (version $19.0, \mathrm{IBM}$ ) software, and a $\mathrm{P}$ value of $<0.05$ or $<0.0025$ (for Spearman only) was considered statistically significant.

\section{Results}

In total, 54 female patients [mean age: 14.1 years; standard deviation (SD): 2.1 ] and 9 male patients (15.9 years; 1.6 ) were included in the study. The average Cobb's angle was $45.9^{\circ}$ (SD: $9.9^{\circ}$ ) for female patients and $47.8^{\circ}$ (SD: $16.0^{\circ}$ ) for male patients. A single thoracic curve was present in 33 patients, whereas double right thoracic and left lumbar curves were present in 30 patients. Six patients had received prior treatment, among whom four patients had received physiotherapy (two patients each for 1 and 2 years), and two patients had received brace treatment (one patient each for 1 and 2 years). All patients self-reported having sedentary lives because of high academic responsibility and physical restrictions (Table 1).

Of the 63 patients in this study, 57 achieved maximal physical capacity (respiratory exchange ratio: $>1.00$ at maximal workload), whereas the other 6 received submaximal exercise tests. Fufty nine patients demonstrated signs of lower extremity fatigue and exhaustion at maximal workload, and 4 experienced dyspnea. Compared with the male patients, female patients demonstrated significantly higher maximal load and lower peak oxygen uptake, oxygen uptake at anaerobic threshold, and oxygen pulse (Table 1). Moreover, the degree of spinal curvature was not correlated with these cardiorespiratory parameters.

The SRS-22 domain scores in the total population ranged from 2.32 (SD: 0.90) to 2.85 (SD: 0.46) and were similar among patients with single and double thoracic curves (Table 2). On stratification, the scores of patients with moderate $\left(<50^{\circ}\right)$ and severe curves $\left(\geq 50^{\circ}\right)(24)$ were found to be similar (Table 2). No statistically significant differences were observed in the SRS-22 scores in all the domains between the male and female patients (Table 2); however, all the domain scores were $<3.0$, except for the function scores of male patients, which indicate the poor quality of life. Self-image domain scores were the lowest of all domain scores among the male patients, whereas pain scores were the lowest among the female patients.

Spearman correlation analysis revealed a significant positive correlation peak oxygen uptake normalized by body weight and the SRS-22 scores in female patients (Table 3), as reflected by the function $(\mathrm{r}=0.511, \mathrm{P}<0.001)$, pain $(\mathrm{r}=0.418$, $\mathrm{P}=0.002)$, mental health $(\mathrm{r}=0.536, \mathrm{P}<0.001)$ and subtotal $(r=0.618, P<0.001)$ scores. Significant correlations were also found between oxygen uptake at anaerobic threshold normalized by body weight and the SRS-22 scores in female patients, as reflected by the function $(\mathrm{r}=0.404, \mathrm{P}=0.002)$, pain $(\mathrm{r}=0.455, \mathrm{P}=0.001)$, and subtotal $(\mathrm{r}=0.501, \mathrm{P}<0.001)$ scores, along with respiratory exchange ratio reflected by subtotal $(\mathrm{r}=0.464, \mathrm{P}<0.001)$ score. In addition, the area under the ROC curve for the oxygen uptake at anaerobic threshold, the peak oxygen uptake, and the respiratory exchange ratio at peak oxygen uptake was $0.773[5 \%$ confidence interval (CI): 0.643-0.904] 0.813 (95\% CI: $0.695-0.931)$ and 0.820 (95\% CI: 0.704-0.937), respectively (Table 4 and Figure 2).

\section{Discussion}

Spine deformity in patients with idiopathic scoliosis, especially in adolescent patients, negatively affects the quality of life $(5,8)$. Reduced physical capacity among 
Table 1 Anthropometric, radiographic, and cardiopulmonary exercise testing data in adolescent idiopathic scoliosis patients

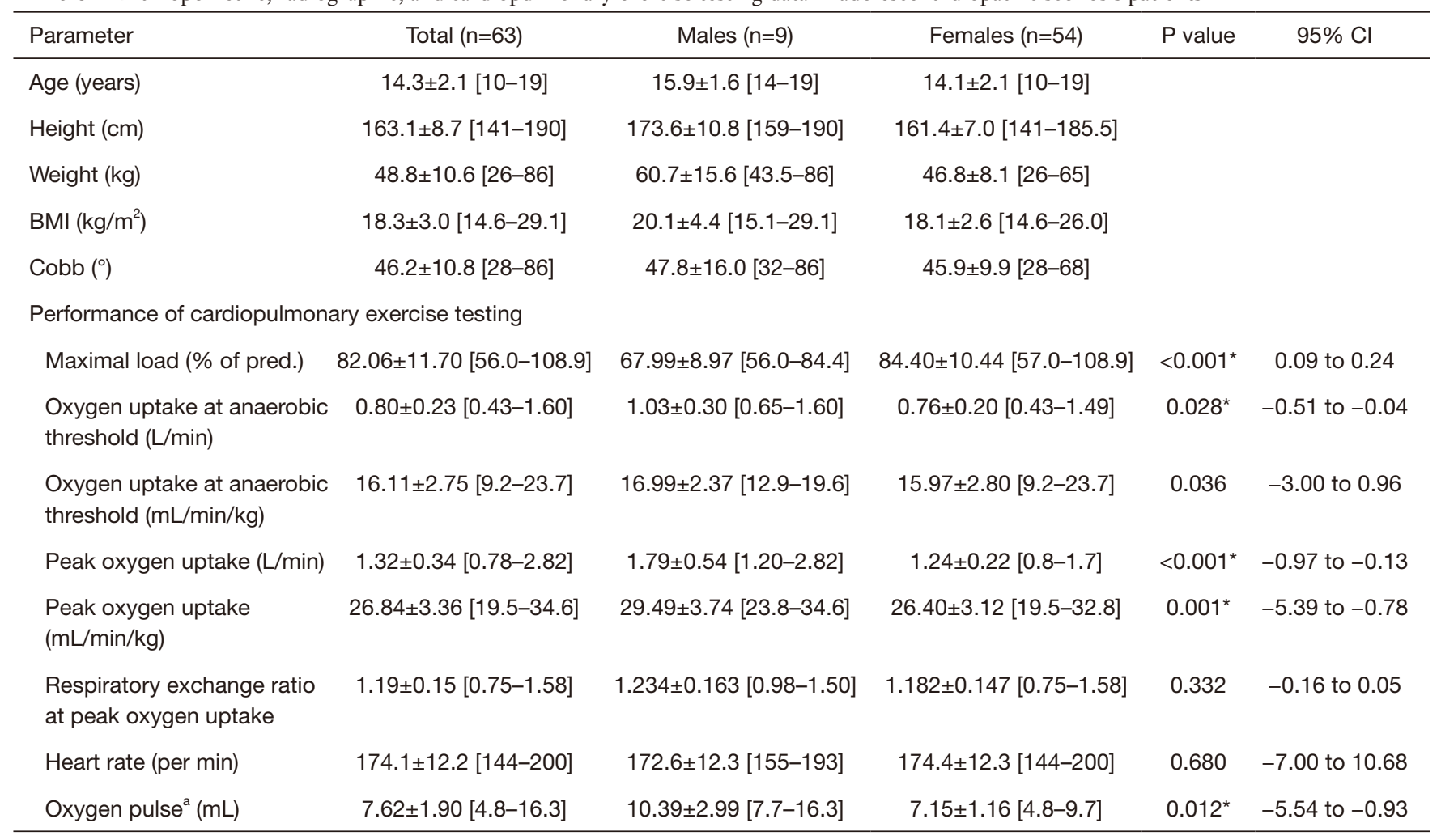

All the values are presented as mean \pm standard deviation (range); $\mathrm{P}$ values were for tests of the differences between male and female patients. a, data were at peak oxygen uptake. *, significant use of independent sample $t$-test.

Table 2 Scoliosis Research Society-22 scores of the total sample and by sex

\begin{tabular}{lccccccccc}
\hline $\begin{array}{l}\text { Scoliosis Research } \\
\text { Society-22 Domain }\end{array}$ & Total & $\begin{array}{c}\text { Single thoracic } \\
\text { curves }(\mathrm{N}=33)\end{array}$ & $\begin{array}{c}\text { Double curves } \\
(\mathrm{N}=30)\end{array}$ & $\begin{array}{c}28^{\circ}-49^{\circ} \\
(\mathrm{N}=38)\end{array}$ & $\begin{array}{c}50^{\circ}-86^{\circ} \\
(\mathrm{N}=25)\end{array}$ & $\begin{array}{c}\text { Male } \\
(\mathrm{n}=9)\end{array}$ & $\begin{array}{c}\text { Female } \\
(\mathrm{n}=54)\end{array}$ & $\begin{array}{c}\mathrm{P} \text { value } \\
95 \% \mathrm{Cl}\end{array}$ \\
\hline Function & $2.70 \pm 0.65$ & $2.67 \pm 0.50$ & $2.72 \pm 0.80$ & $2.63 \pm 0.52$ & $2.78 \pm 0.82$ & $3.16 \pm 0.85$ & $2.62 \pm 0.59$ & 0.099 & -1.32 to 0.06 \\
Pain & $2.32 \pm 0.90$ & $2.18 \pm 0.68$ & $2.47 \pm 1.08$ & $2.21 \pm 0.76$ & $2.49 \pm 1.07$ & $2.91 \pm 1.32$ & $2.22 \pm 0.78$ & 0.159 & -1.71 to 0.33 \\
Self-image & $2.39 \pm 0.68$ & $2.44 \pm 0.78$ & $2.33 \pm 0.55$ & $2.36 \pm 0.72$ & $2.42 \pm 0.61$ & $2.49 \pm 0.94$ & $2.37 \pm 0.63$ & 0.631 & -0.61 to 0.37 \\
Mental health & $2.85 \pm 0.46$ & $2.82 \pm 0.37$ & $2.88 \pm 0.54$ & $2.82 \pm 0.35$ & $2.90 \pm 0.59$ & $2.87 \pm 0.42$ & $2.85 \pm 0.47$ & 0.912 & -0.35 to 0.31 \\
Subtotal & $2.56 \pm 0.55$ & $2.53 \pm 0.43$ & $2.60 \pm 0.66$ & $2.51 \pm 0.45$ & $2.65 \pm 0.67$ & $2.86 \pm 0.70$ & $2.51 \pm 0.51$ & 0.195 & -0.73 to 0.05 \\
\hline
\end{tabular}

All the values are given in terms of the mean and standard deviation; $\mathrm{P}$ values were for tests of the difference between male and female patients.

patients with adolescent idiopathic scoliosis has been reported in the literature (10-12). However, not many studies have investigated the effect of physical capacity on the quality of life in such patients.

In this study, 54 female and 9 male patients exhibited a peak oxygen uptake value of $<35 \mathrm{~mL} / \mathrm{kg} / \mathrm{min}$, which is lower than the expected value for adolescents not engaging in regular aerobic exercise $(10,25)$. This result indicated that the physical capacity was reduced in patients with adolescent idiopathic scoliosis because peak oxygen uptake is a crucial parameter of functional impairment or aerobic capacity (19). This finding is consistent with those of most existing studies $(10,11,13,15)$, except those of Leech et al. (26) and Bas et al. (13), who reported similar maximal oxygen uptake among scoliotic adolescents with mild curves and healthy peers. 
Table 3 Spearman's correlation analysis of Scoliosis Research Society-22 score with cardiopulmonary exercise test measures

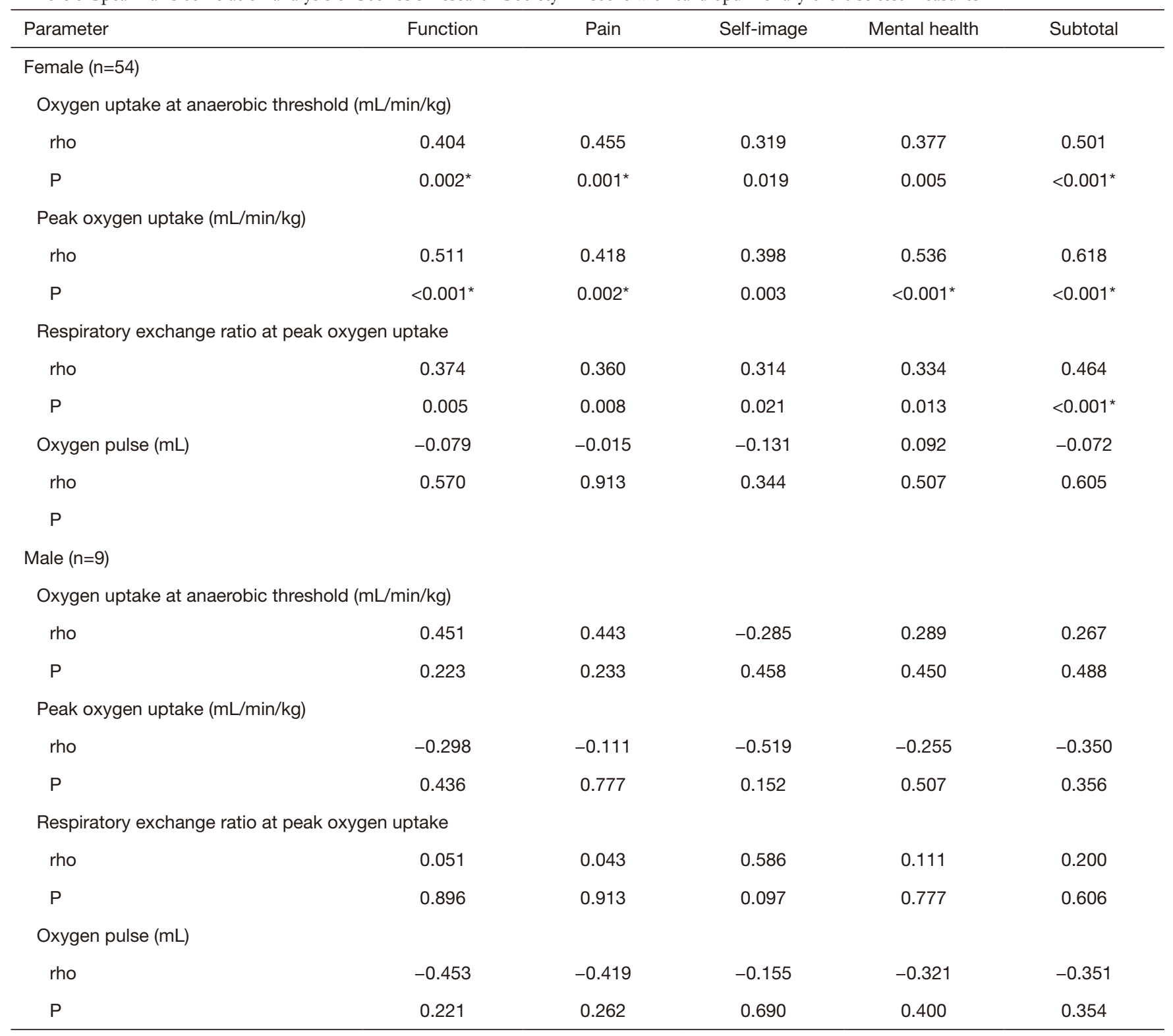

Rho is Spearman's correlation coefficient. Oxygen update and respiratory exchange ratio have statistically significant rho and thus were included in the multiple regression analysis used in the ROC analysis. *, sificant correlation by Spearman's correlation test, $\mathrm{P}<0.0025$.

Table 4 ROC analysis of Scoliosis Research Society-22 subtotal score with cardiopulmonary exercise test measures in female patients

\begin{tabular}{lccc}
\hline Parameter & Area under ROC curve & P value & 95\% Cl \\
\hline Oxygen uptake at anaerobic threshold $(\mathrm{mL} / \mathrm{min} / \mathrm{kg})$ & 0.773 & 0.001 & $<.643-0.904$ \\
Peak oxygen uptake $(\mathrm{mL} / \mathrm{min} / \mathrm{kg})$ & 0.813 & $<0.001$ & $0.695-0.931$ \\
Respiratory exchange ratio at peak oxygen uptake & 0.820 & $<0.001$ & $0.704-0.937$ \\
\hline
\end{tabular}




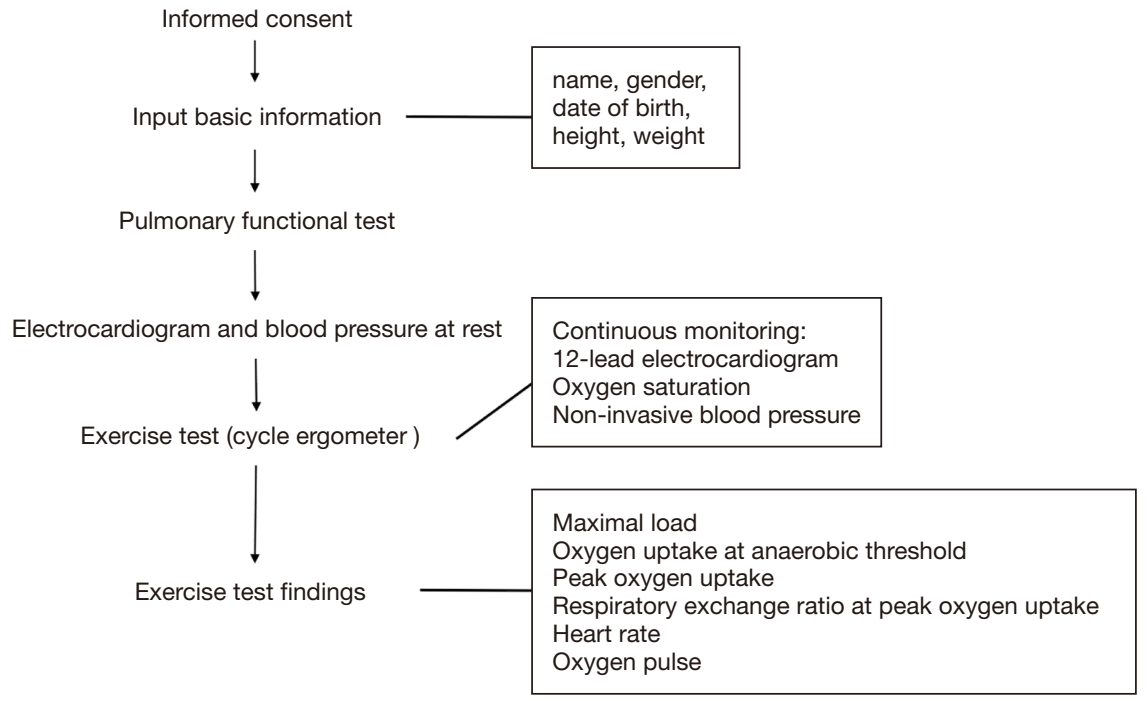

Figure 2 ROC curve of Scoliosis Research Society-22 subtotal score with cardiopulmonary exercise test measures in female patients.

Our data revealed that both male and female patients with adolescent idiopathic scoliosis achieved low scores in all the domains of the SRS-22 questionnaire (<3.0, except for function scores among male patients) (18), which is indicative of their poor quality of life. This observation is consistent with the findings of the existing literature $(8,27)$ and also with one of the proven effects of scoliosis. Although our data did not reveal statistically significant differences between male and female patients in all domains, the differences in the function (0.54), pain (0.69), and subtotal (0.35) scores remained within the clinically relevant range (18). In addition, the small sample size of men in this study could have inhibited the detection of relevant differences, although earlier studies suggested gender-based differences in patients with adolescent idiopathic scoliosis $(17,18)$. The correlations among female patients were further explored, which adequately supported our findings.

Because fewer men and insignificant sex differences were observed in the quality of life evaluation (18), we analyzed the correlation between cardiopulmonary exercise test parameters and the SRS-22 scores only for female patients. A significant correlation was observed between peak oxygen uptake normalized by body weight (peak oxygen uptake $\mathrm{mL} / \mathrm{min} / \mathrm{kg}$ ), which was the key parameter representing physical capacity and SRS-22 domains. It showed that peak oxygen uptake positively correlated with function, pain, mental health, and subtotal scores of the SRS-22. Our findings indicated that patient activities, pain, mental health, and overall function are correlated with physical capacity. Meanwhile, the value of oxygen uptake at anaerobic threshold normalized by body weight (oxygen uptake at anaerobic threshold $/ \mathrm{kg}$ ) revealed a significant positive correlation with function, pain, and subtotal scores. Anaerobic threshold is defined as the level of oxygen uptake during exercise above which aerobic energy production is supplemented by anaerobic mechanisms and is reflected by an increase in lactate and lactate-to-pyruvate in muscles and arterial blood (21). Based on its definition and physiological effects, the anaerobic threshold is considered an important determinant for work endurance potential (21). Our study indicated an early anaerobic threshold in patients with adolescent idiopathic scoliosis would correlate with a lower patient's capacity for sustained activity and quality of life. Also, the respiratory exchange ratio at maximal physical effort was found to be positively correlated with overall impairment, as reflected by the subtotal scores. The respiratory exchange ratio varied overtime during the cardiopulmonary exercise test, which usually reduced slightly after the start of the exercise, followed by an increase $(<1.0)$, as muscle respiration contributes greatly to oxygen use in other parts of the body (e.g., fats). In the steepening stage, the rate of lactic acid production overruns bicarbonate's buffering capacity, resulting in a steeper respiratory exchange ratio (21). Therefore, the respiratory exchange ratio can be used as an indicator of exercise intensity. Our findings indicated that overall patient function is correlated with exercise intensity. In addition, muscle strength is a significant contributor to exercise capacity (19); however, 59 out of 63 patients demonstrated 
signs of lower extremity fatigue at maximal load in our study. Considering the BMI values of these patients $\left(18.1 \pm 2.6 \mathrm{~kg} / \mathrm{m}^{2}\right.$ for female patients and $20.1 \pm 4.4 \mathrm{~kg} / \mathrm{m}^{2}$ for male patients), peripheral muscle weakness was assumed to contribute to the performance during the cardiopulmonary exercise test. However, physical fitness can affect the substrate utilization pattern, allowing for more work performance before glycogen depletion and consequent exhaustion (21). Earlier studies have demonstrated that exercise improves patients' physical capacity with mild and moderate adolescent idiopathic scoliosis (13). Shen et al. (14) reported that patients who regularly performed aerobic exercise demonstrated better performance in the cardiopulmonary exercise test. Therefore, aerobic exercise and muscle strength training may benefit patients with adolescent idiopathic scoliosis to maintain cardiovascular and peripheral muscle conditioning $(13,14)$, as well as to maintain fitness for achieving a better quality of life. Besides, our findings indicated both male and female patients with adolescent idiopathic scoliosis had pain and poorer mental health, which may affect the efficacy of exercise. Therefore, the pain and mental health should be improved before applying exercise for improving the quality of life.

This study was not without limitations. First, the retrospective study design, and some data, such as the type of treatment and physical activity level, were not collected. Second, the sample size was relatively small, especially in the male cohort. Third, the predictive model demonstrated moderate discrimination with a wide $95 \%$ CI. Fourth, the study did not include an age-matched control group, limiting a reliable evaluation of the influence of spinal deformity on the cardiopulmonary parameters. Last, lack of comparison with the control group hindered the investigation of whether or not the cardiopulmonary function was truly impaired in the patients included in this study. However, the retrospective study design possibly suggests a temporal relation between physical capacity and quality of life. Nevertheless, further studies with larger sample sizes and a prospective study design, ideally intervention trials, are warranted to investigate whether physical capacity development improves the quality of life in patients with idiopathic scoliosis.

\section{Conclusions}

In summary, the physical capacity and capacity for exercise intensity and endurance correlated with the quality of life of patients with adolescent idiopathic scoliosis. Our results imply that exercise may help improve the quality of life of patients with adolescent idiopathic scoliosis. Exercise can be recommended as supportive therapy for patients with adolescent idiopathic scoliosis. However, we recommend further studies with larger sample sizes to support these findings.

\section{Acknowledgments}

Funding: None.

\section{Footnote}

Reporting Checklist: The authors have completed the STROBE reporting checklist. Available at http://dx.doi. org/10.21037/apm-20-2624

Data Sharing Statement: Available at http://dx.doi. org/10.21037/apm-20-2624

Peer Review File: Available at http://dx.doi.org/10.21037/ apm-20-2624

Conflicts of Interest: All authors have completed the ICMJE uniform disclosure form (available at http://dx.doi. org/10.21037/apm-20-2624). The authors have no conflicts of interest to declare.

Ethical Statement: The authors are accountable for all aspects of the work in ensuring that questions related to the accuracy or integrity of any part of the work are appropriately investigated and resolved. The study was conducted in accordance with the Declaration of Helsinki (as revised in 2013). The study was approved by the Institutional Review Board (IRB) of Peking Union Medical College Hospital (PUMCH) (NO. S-K209). Written informed consent was obtained from all the individual participants or their guardians included in this study.

Open Access Statement: This is an Open Access article distributed in accordance with the Creative Commons Attribution-NonCommercial-NoDerivs 4.0 International License (CC BY-NC-ND 4.0), which permits the noncommercial replication and distribution of the article with the strict proviso that no changes or edits are made and the original work is properly cited (including links to both the formal publication through the relevant DOI and the license). See: https://creativecommons.org/licenses/by-nc-nd/4.0/. 


\section{References}

1. Lonstein JE. Adolescent idiopathic scoliosis. Lancet 1994;344:1407-12.

2. Riseborough EJ, Wynne-Davies R. A genetic survey of idiopathic scoliosis in boston, massachusetts. J Bone Joint Surg Am 1973;5 5:974-82.

3. Konieczny MR, Senyurt H, Krauspe R. Epidemiology of adolescent idiopathic scoliosis. J Child Orthop 2013;7:3-9.

4. Asher M, Min Lai S, Burton D, et al. The reliability and concurrent validity of the scoliosis research society-22 patient questionnaire for idiopathic scoliosis. Spine (Phila Pa 1976) 2003;28:63-9.

5. Asher M, Min Lai S, Burton D, et al. Discrimination validity of the scoliosis research society-22 patient questionnaire: Relationship to idiopathic scoliosis curve pattern and curve size. Spine (Phila Pa 1976) 2003;28:74-8.

6. Bagó J, Perez-Grueso FJ, Les E, et al. Minimal important differences of the srs-22 patient questionnaire following surgical treatment of idiopathic scoliosis. Eur Spine J 2009; 18:1898-904.

7. Parent EC, Dang R, Hill D, et al. Score distribution of the scoliosis research society-22 questionnaire in subgroups of patients of all ages with idiopathic scoliosis. Spine (Phila Pa 1976) 2010;35:568-77.

8. Verma K, Lonner B, Hoashi JS, et al. Demographic factors affect scoliosis research society-22 performance in healthy adolescents: A comparative baseline for adolescents with idiopathic scoliosis. Spine (Phila Pa 1976) 2010;35:2134-9.

9. Newton PO, Faro FD, Gollogly S, et al. Results of preoperative pulmonary function testing of adolescents with idiopathic scoliosis. A study of six hundred and thirtyone patients. J Bone Joint Surg Am 2005;87:1937-46.

10. Barrios C, Perez-Encinas C, Maruenda JI, et al. Significant ventilatory functional restriction in adolescents with mild or moderate scoliosis during maximal exercise tolerance test. Spine (Phila Pa 1976) 2005;30:1610-5.

11. Czaprowski D, Kotwicki T, Biernat R, et al. Physical capacity of girls with mild and moderate idiopathic scoliosis: Influence of the size, length and number of curvatures. Eur Spine J 2012;21:1099-105.

12. dos Santos Alves VL, Stirbulov R, Avanzi O. Impact of a physical rehabilitation program on the respiratory function of adolescents with idiopathic scoliosis. Chest 2006;130:500-5.

13. Bas P, Romagnoli M, Gomez-Cabrera MC, et al. Beneficial effects of aerobic training in adolescent patients with moderate idiopathic scoliosis. Eur Spine J 2011;20 Suppl 3:415-9.

14. Shen J, Lin Y, Luo J, et al. Cardiopulmonary exercise testing in patients with idiopathic scoliosis. J Bone Joint
Surg Am 2016;98:1614-22.

15. Sperandio EF, Alexandre AS, Yi LC, et al. Functional aerobic exercise capacity limitation in adolescent idiopathic scoliosis. Spine J 2014;14:2366-72.

16. Thomen RP, Woods JC, Sturm PF, et al. Lung microstructure in adolescent idiopathic scoliosis before and after posterior spinal fusion. PLoS One 2020;15:e0240265.

17. Ameri Mahabadi E, Ghandehari H, Mahdavi SM, et al. Adolescent idiopathic scoliosis: Males versus females. Shafa Ortho J 2015;2.

18. Roberts DW, Savage JW, Schwartz DG, et al. Malefemale differences in scoliosis research society-30 scores in adolescent idiopathic scoliosis. Spine (Phila $\mathrm{Pa}$ 1976) 2011;36:E53-9.

19. American Thoracic Society; American College of Chest Physicians. ATS/ACCP Statement on cardiopulmonary exercise testing. Am J Respir Crit Care Med 2003;167:211-77.

20. Hawkins MN, Raven PB, Snell PG, et al. Maximal oxygen uptake as a parametric measure of cardiorespiratory capacity. Med Sci Sports Exerc 2007;39:103-7.

21. Wasserman K. Principles of exercise testing and interpretation: Including pathophysiology and clinical applications. Wolters Kluwer Health/Lippincott Williams \& Wilkins; 2012.

22. Srs-22 patient questionnaire. Available online: http://www. srs.org/professionals/outcomes/srs-22.pdf

23. Srs-22 patient questionnaire scored sample. Available online: http://www.srs.org/professionals/outcomes/srs-22_ sample.pdf

24. Weinstein SL, Dolan LA, Cheng JC, et al. Adolescent idiopathic scoliosis. Lancet 2008;371:1527-37.

25. Astrand PO, Rodahl K. Textbook of work physiology: Physiological bases of exercise. New York: McGraw-Hill; 1986.

26. Leech JA, Ernst P, Rogala EJ, et al. Cardiorespiratory status in relation to mild deformity in adolescent idiopathic scoliosis. J Pediatr 1985;106:143-9.

27. Merola AA, Haher TR, Brkaric M, et al. A multicenter study of the outcomes of the surgical treatment of adolescent idiopathic scoliosis using the scoliosis research society (srs) outcome instrument. Spine (Phila Pa 1976) 2002;27:2046-51.

Cite this article as: Cong $\mathrm{H}$, Chen L, Shen J, Yuan W, Lin Y, Liu Z, Liu S, Zhang L. Is physical capacity correlated with health-related quality of life in patients with adolescent idiopathic scoliosis? Ann Palliat Med 2021;10(6):6220-6227. doi: 10.21037/apm-20-2624 